\title{
A Study on Factors Influencing Investing in Mutual Fund with Special Reference to Mysore District
}

\author{
B. Hrushikesh ${ }^{1}$ and Dr. A.Kaboor ${ }^{2}$ \\ ${ }^{1}$ Part Time Research Scholar, Department of Commerce, Bhararthiar University, Coimbatore, INDIA \\ ${ }^{2}$ Assistant Professor, Department of Commerce, CBM Arts College, Coimbatore, INDIA \\ ${ }^{1}$ Corresponding Author: hrushi_rao@yahoo.com
}

\begin{abstract}
Financial reforms have great impact not only on Indian financial system but also on Indian economy as a whole. Three sectors of Indian financial system that are greatly influenced and witnessed substantial growth are banking, insurance, mutual fund. During the last decade, these three sectors have seen various developments. Mutual funds are investment avenues for the investors. Mutual fund is the pool of money of several investors to invest in financial investment such as stock, government securities and debentures. There are various sources of information like Television, internet, newspaper and also All India mutual fund association has published two booklets "Making mutual funds works for you" and "Selling mutual funds made easy". These two publications translated into regional languages and distributed widely .To what extent do these sources of information influence the investors? The bankers or agents or financial advisers rendered services like providing knowledge about tax laws, new scheme, sorting out the problem, providing of consultancy. These are essential to strengthen or promote the mutual fund. Are the investors really satisfied with their services? If so, to what extent? Every investor has different investment avenues to invest in. There are some factors such as tax benefits, safety and liquidity, which influence behaviour of investors in selection of mutual fund (Prasada Rao and Vedantam Saikia, 2006). Do these factors influence behaviour of investors in the selection of mutual fund?, In this regard the present study is conducted to list the factors influencing investing in mutual funds in Mysore district.
\end{abstract}

Keywords-- Financial Reforms, Mutual Fund, Television, Internet, Newspaper, Mysore District

\section{INTRODUCTION}

\section{Review of Literature}

Brad Barber, Terrance Odean, Luzheng (2000) conducted a study entitled "The Behaviour of Mutual fund investors". They took a sampling of over 30,000 households with accounts at a large U.S discount broker for six years ending in 1996. They concluded that the representative heuristic leads investors to buy past winners, the disposition effect renders investors reluctant to sell their losers, and framing effects cause investors to react differently to various forms of fund expenses and also reveals how selling, winning fund investments and neglecting a funds operating expense ratio when purchasing a fund is clearly counter productive.

Kozup, John, Howlett, Elizabeth Pagano Micheal (2008) conducted a study entitled "The Effects of summary information on consumer perceptions on Mutual fund characteristics", They examined investors decisions how to best invest especially for retirement. They found that while investors continue to place so much emphasis on prior performance, the provision for supplementary information and investment knowledge too influence perceptions and evaluations of mutual funds.

Umaya Salma Shajahan and Archana (2008) conducted a study entitled, "A study on factors influencing the investments on mutual funds in Salem District of Tamilnadu". The study was conducted with the prime objective to determine the factors which influence investors to invest in mutual fund. A sample was taken of private chit fund, using a structured questionnaire. The percentage analysis, chisquare analysis and weighted average technique were employed in this study. The study concluded that the factors such as safety, risk, high return played a major role in influencing investor to invest in mutual fund. It is also found that liquidity, tax benefits, low risk, safety are attributed to selected mutual fund schemes.

Rao (2011) carried out a study on "Analysis of individual investor behavior towards Mutual Fund Scheme". In this study, the author correlates the investor knowledge and adoption of different schemes with educational level. According to the research, the greater the level of education, the greater is the level of risk tolerance. This finding was seen to be in accordance to the hypothesis developed in previous researches, i.e., a positive relationship was present between educational level and financial risk tolerance.

\section{METHODOLOGY}

The data required for the study is primary in nature. Questionnaire method has been used in the collection of data.

\section{Sampling}

Stratified Random sampling method has been followed to choose from the investor list furnished by the mutual fund certified agents as well as the investor forum. 


\section{Sampling Procedure}

Among the districts of Karnataka Mysore has been selected for the study because if the following reasons. Mysore has a core population of 920,000 coming under the city corporation and outgrowths and Mysore urban agglomeration has a population of 983,000. According to 2011 census, Mysore was the largest no metropolitan city in India and had the highest basic infrastructure index of 2.846. One of the major industrial in the proximity of Mysore is Nanjangud which will be Satellite town to Mysore. $\mathrm{t}$. With this background Mysore has been selected for the study and by using stratified Random sampling method 700 investors from the investor list furnished by the mutual fund agents as well as the investor forum the research is carried out. Data reported in the study is the result of the response from 613 investors.

\section{FACTORS INFLUENCING INVESTMENTS IN MUTUAL FUNDS}

The facts obtained for the study were analyzed by using factor analysis for the identification of the main factors considered by an investor, while deciding upon the particulars of mutual fund. Factor analysis involves identification of common dimension of factors from the observed set of variables that have a high level of correlation with the observed and seemingly unrelated variables but none among the factors. Principal Component Analysis is a commonly used method to group the variables under a few unconnected factors. Variables having a factor loading of greater than 0.6 are grouped under one factor. A factor is the correlation between the variables concerned and the specified factor.
It is, therefore, key to understand the nature of a particular factor. In the process of this study, the principal component analysis has been employed. The objective is to regroup most of the original variables into the minimum of factors possible. The factors are, hence, extracted in such a way that the factors axes are maintained at 90 degrees to each other, so that each factor is independent of the others' influence. A factor is basically a linear combination of variables. A predominant and important concept in factor analysis is the rotation of factors. The concept of varimax rotation has been used to simplify the factor structure. Only the factors having Eigen values greater than unity have been considered. An Eigen value is a column sum of the squares of a factor and represents the variance of a factor. Those factor loadings greater than 0.5 have been chosen and loaded on the extracted ones. The final step in the factor analysis study has been the nomenclature of the factors with appropriateness to represent the basic variables.

Table 1 shows the two tests which indicate the suitability of the data for factor analysis. The KaiserOlkin measure of sampling Adequacy is a statistic which indicates the proportion of variance in the variables, which is common variance, i.e which might be caused by underlying factors. High values (close to 1.0) generally indicate that a Factor Analysis may be useful for our data.

Bartlett's Test of sphericity indicates whether our correlation matrix is an identity matrix, which would indicate that our variables are unrelated. The significance level gives the result of the test. Very small values(less than 0.05 ) indicate that there are probably significant relationships among our variables.

TABLE 1

KMO AND BARTLETTS TEST

\begin{tabular}{|c|c|}
\hline \multicolumn{2}{|c|}{ Test for the suitability of Data } \\
\hline \multicolumn{2}{|c|}{ KMO and Bartletts Test } \\
\hline Kaiser-Meyer-olkin measure of sampling Adequacy & 0.782 \\
\hline Bartletts Test of sphericity Approx. chi-square & 4876.740 \\
\hline Df & 153 \\
\hline Sig & 0.000 \\
\hline
\end{tabular}

TABLE 2

FACTORS AND VARIANCE ANALYSIS

\begin{tabular}{|c|c|c|c|}
\hline \multirow{2}{*}{ Component } & Initial Eigen values & \multirow{2}{*}{ \% of Variance } & \multirow{2}{*}{ Cumulative \% } \\
\cline { 2 - 4 } & Total & 29.103 & 29.103 \\
\hline F1 & 5.239 & 16.560 & 45.663 \\
\hline F2 & 2.981 & 9.578 & 55.241 \\
\hline F3 & 1.724 & 6.353 & 61.594 \\
\hline
\end{tabular}

The Factor Analysis using Varimax Rotations, results in four derived factors with each having an Eigen value of greater than 1. From Table No 3. In the RCM, only those variables which have a factor loading greater than 0.5 are grouped under their respective derived factors. Hence, the 18 different variables (i) Professional management (ii) Mutual fund Regulations (iii) Convenience (iv) Low transaction cost (v) Information 
Adequacy (vi) Choice of Schemes (vii) Tax Benefits (viii) Real Earnings of the company (ix) Growth prospect of the company (x) Return on Investment (xi) Repurchase facility (xii) Past Record of Organization (xiii) Credit Rating (xiv) Easy Transferability (xv) Business condition at the time (xvi) Lock in period (xvii) Grievance redressal (xviii) Investor Right. Adherence are then loaded on Four derived factors.

Table 2 refers to Factor 1 which has an Eigen value of 5.239 and $29.103 \%$ of the variance. The Eigen value of the second, third and fourth is 2.981, 1.724 and 1.144 , respectively. The total variance accounted by the four factors is 61.594, which is acceptable and thus, establishes the validity of the study.

TABLE 3

ROTATED COMPONENT MATRIX

\begin{tabular}{|c|c|c|c|c|}
\hline Labels & F1 & F2 & F3 & F4 \\
\hline DE9 & $\mathbf{0 . 8 2 3}$ & 0.078 & -0.037 & 0.123 \\
\hline DE12 & $\mathbf{0 . 7 6 3}$ & 0.256 & 0.054 & -0.012 \\
\hline DE11 & $\mathbf{0 . 7 6 1}$ & 0.191 & -0.020 & 0.053 \\
\hline DE10 & $\mathbf{0 . 7 2 2}$ & 0.098 & -0.162 & 0.161 \\
\hline DE8 & $\mathbf{0 . 5 9 8}$ & -0.051 & 0.094 & 0.446 \\
\hline DE14 & $\mathbf{0 . 5 8 2}$ & 0.545 & 0.077 & -0.070 \\
\hline DE13 & $\mathbf{0 . 5 3 2}$ & 0.522 & 0.197 & -0.120 \\
\hline DE15 & 0.185 & $\mathbf{0 . 7 6 0}$ & 0.055 & -0.035 \\
\hline DE18 & 0.081 & $\mathbf{0 . 7 5 8}$ & 0.031 & 0.043 \\
\hline DE16 & 0.106 & $\mathbf{0 . 7 3 7}$ & -0.023 & 0.293 \\
\hline DE17 & 0.152 & $\mathbf{0 . 6 5 4}$ & 0.066 & 0.313 \\
\hline DE1 & 0.035 & 0.022 & $\mathbf{0 . 8 3 4}$ & 0.090 \\
\hline DE2 & -0.068 & 0.019 & $\mathbf{0 . 7 8 4}$ & 0.295 \\
\hline DE3 & 0.026 & 0.059 & $\mathbf{0 . 7 3 4}$ & 0.106 \\
\hline DE5 & -0.059 & 0.173 & $\mathbf{0 . 7 2 7}$ & 0.145 \\
\hline DE6 & 0.232 & 0.004 & 0.211 & $\mathbf{0 . 7 3 8}$ \\
\hline DE7 & 0.267 & 0.171 & 0.261 & $\mathbf{0 . 7 2 3}$ \\
\hline DE4 & -0.103 & 0.148 & 0.517 & $\mathbf{0 . 5 8 0}$ \\
\hline
\end{tabular}

Naming the Factors

All the Four factors extracted have been given names on the basis of variables included in each case.

They have been named as.

F1: Mutual Fund Company

F2: Investor Grievance

F3: Mutual Fund Regulations

F4: Mutual Fund Product Services. The structure of these four factors has been discussed individually in detail.

TABLE 4

F1: MUTUAL FUND COMPANY

\begin{tabular}{|c|l|c|}
\hline Labels & \multicolumn{1}{|c|}{ Variables } & Loadings \\
\hline DE9 & Growth prospects of the company & 0.823 \\
\hline DE12 & Past record of the organization & 0.763 \\
\hline DE11 & Repurchase Facility & 0.761 \\
\hline DE10 & Return on Investment & 0.722 \\
\hline DE8 & Real Earnings of the company & 0.598 \\
\hline DE14 & Easy Transferability & 0.582 \\
\hline DE13 & Credit Rating & 0.532 \\
\hline
\end{tabular}

The rotated matrix has revealed this factor as most the important one, with the highest Eigen value 5.239. Totally, seven variables have been loaded on to this factor and are arranged according to their loading values. The variables composed of this factor and factor loading are given in the above table.

The Table reveals that the variable "Growth Prospects of the Company "has got the highest loading of
0.823. This has been closely followed by the variables "Past record of the organization" (0.763) and "Repurchase Facility" (0.761). The fourth variable "Return on Investment" (0.722) is followed by "Real Earnings of the company" (0.598) and "Easy Transferability" (0.582). The Last Variable "Credit Rating" has the loading of 0.532 . The loading pattern of the second and the third variables reveals an association 
among the variables as Past Record of the organization, Repurchase facility. The variable 'Return on investment' also loaded on to this factor with loading of $0.722 \mathrm{might}$ be due to the correlation with the first three variables loaded on this factor and its similar nature to the underlying factor.

TABLE 5

F2: INVESTOR GRIEVANCE

\begin{tabular}{|c|l|c|}
\hline Labels & \multicolumn{1}{|c|}{ Variables } & Loadings \\
\hline DE15 & Business Condition & 0.760 \\
\hline DE18 & Investor right adherence & 0.758 \\
\hline DE16 & Lock in period & 0.737 \\
\hline DE17 & Grievance redressal & 0.654 \\
\hline
\end{tabular}

The rotated matrix has revealed this factor as the second most important factor, with the highest Eigen value of 2.981. In total, four variables have been loaded on this factor and are arranged according to their loading values. The variables composing this factor and factor loading are given in the above table.

The Table shows that the variable "Business Condition" has got the highest loading of 0.760 . This has been followed by the variables "Investor right adherence" with a loading of 0.758 , "Lock in period" with 0.737 and Grievance redressal with 0.654 .
The factor clearly brings out the various aspects of the impact of variables on investor grievance while investing in mutual fund. The loading pattern of this factor indicates that these exists a close relationship among the first three variables, i.e. Business condition, investor right adherence and lock in period. The first three variables have the greatest impact on the investors Grievances. The last variable 'Grievance Redressal' also plays a role in investing in mutual fund with a load value 0.654 .

TABLE 6

F3: MUTUAL FUND REGULATIONS

\begin{tabular}{|c|l|c|}
\hline Labels & \multicolumn{1}{|c|}{ Variables } & Loadings \\
\hline DE1 & Professional management & 0.834 \\
\hline DE2 & Mutual fund regulations & 0.784 \\
\hline DE3 & convenience & 0.734 \\
\hline DE5 & Information Adequacy & 0.727 \\
\hline
\end{tabular}

The rotated matrix has revealed this factor as the third most important factor, with the highest Eigen value of 1.724. In total, three variables have been loaded on this factor and are arranged according to their loading values. The variables composed of this factor and, factor loading are given in the above table.

The Table reveals that the variable, "professional management" has the highest loading of 0.834 . This has been followed by the variables 'Mutual
Fund regulations' with a loading 0.784 and "Convenience" with 0.734 .

The Factor describes the various aspects of mutual fund regulations. The loading pattern on this factor clearly states that there is an association between the variables "Mutual Fund Regulations" and the variable "Convenience". In the case of Mutual Fund Regulations, the professional management is the most important variable of all the factors.

TABLE 7

F4: MUTUAL FUND PRODUCT SERVICES

\begin{tabular}{|c|l|c|}
\hline Labels & \multicolumn{1}{|c|}{ Variables } & Loadings \\
\hline DE6 & Choice of schemes & 0.738 \\
\hline DE5 & Information adequacy & 0.727 \\
\hline DE7 & Tax Benefits & 0.723 \\
\hline DE4 & Low Transaction cost & 0.580 \\
\hline
\end{tabular}

This is the fourth and last important factor that has emerged in the orthogonal rotation of factors with the highest Eigen value of 1.144. In total, three variables have been loaded on this factor and are arranged according to their loading values. The variables composed of this factor and factor loading are given in the above table.
From the above Table the variable "choice of schemes" has the highest loading of 0.738 . This has been followed by the variables "Information adequacy" and "Tax Benefits" with 0.723 , "Low Transaction cost" with 0.580 .

The Factor explains the various aspects of The loading Pattern of this factor clearly indicates that 
there is an association among the first three variables. The variable 'Choice of Scheme' is the highest one as far as the product services is concerned. The Variables choice of schemes, information adequacy and Tax Benefits have impact on investors.

To sum up the above analysis, the growth prospect of the company attracts the investor while looking the profile of the organization for investment. Almost every investor considered grievance redressal is vital. For the improvement of mutual fund, the effective addressing of grievance redressal can be said to be the major factor on the investor's point of view. It is said that regulations of mutual fund leads mutual fund investor to invest more. The product service is also essential for development of mutual fund.

\section{FACTOR ANALYSIS-RESONS FOR NOT INVESTING MORE IN MUTUAL FUND}

The performance of any mutual fund depends upon two major factors. Firstly, the trends in the capital markets of the country and secondly, the effectiveness of fund managers to time market, i.e., how quickly the fund manager moves out of high beta-coefficient investment on sensing the onset of bearish trend in the markets. Whatever have been the reasons, the majority of the mutual funds, so far, has not been able to come up to the expectations of investors. That is why the investors withdraw their investments from mutual funds or do not intend to invest more in them. In our research, out of 613 investors, 231 are not willing to invest more in mutual funds. The factor analysis is applied to find out the one that predominantly affects the investor who has not invested more in mutual funds future.

A factor is basically a linear combination of variables. A predominant and important concept in factor analysis is the rotation of factors. The concept of varimax rotation has been used to simplify the factor structure. Only the factors having Eigen values greater than unity have been considered. An Eigen value is a column sum of the squares of a factor and represents the variance of a factor. Those factor loadings greater than 0.5 have been chosen and loaded on the extracted ones. The final step in the factor analysis study has been the nomenclature of the factors with appropriateness to represent the basic variables.

TABLE 9

KMO AND BARTLETTS TEST

\begin{tabular}{|c|c|}
\hline \multicolumn{2}{|c|}{ Test for the Suitability of Data } \\
\hline \multicolumn{2}{|c|}{ KMO and Bartletts Test } \\
\hline Kaiser-Meyer-olkin measure of sampling Adequacy & 0.729 \\
\hline Bartletts Test of sphericity Approx. chi-square & 457.537 \\
\hline Df & 28 \\
\hline Sig & 0.000 \\
\hline
\end{tabular}

Table shows the two tests which indicate the suitability of the data for factor Analysis. The kaiserolkin of measure of sampling adequacy is a statistic which indicates the proportion of variance in the variables, It is common variance i.e which might be caused by underlying factors. High values (close to 1.0) generally indicate that a factor analysis may be useful with our data.
Bartlett's test of sphericity indicates whether our correlation matrix is an identify matrix, which would indicate that our variables are unrelated. The significance level gives the result of the test. Very small values (less than 0.05 ) indicate that there are probably significant relationships among our variables.

TABLE 10

ROTATED COMPONENT MATRIX

\begin{tabular}{|c|c|c|}
\hline Labels & F1 & F2 \\
\hline DE7 & & 0.114 \\
\hline DE5 & $\mathbf{0 . 8 3 9}$ & 0.249 \\
\hline DE3 & $\mathbf{0 . 7 6 5}$ & 0.302 \\
\hline DE8 & $\mathbf{0 . 7 1 8}$ & 0.086 \\
\hline DE2 & $\mathbf{0 . 6 9 0}$ & $\mathbf{0 . 8 8 9}$ \\
\hline DE1 & 0.098 & $\mathbf{0 . 7 4 1}$ \\
\hline DE4 & 0.131 & $\mathbf{0 . 6 8 2}$ \\
\hline DE6 & 0.195 & $\mathbf{0 . 5 4 5}$ \\
\hline
\end{tabular}


From the above Table shows that factor analysis using varimax rotations, results in two derived factors with each having an Eigen value of variables which have a factor loading greater than 0.5 are grouped under their respective derived factors. Hence, the 8 different variables (i) Returns from Mutual fund have been less than expected (ii) Professionally expert managers have underperformed (iii) Growth in the unit value has been very low (iv) There is insecurity of investment due to connivance between fund managers and corporate houses (v) Non understanding of certain technical terms and conditions permit the withdrawal of scheme by the fund abruptly (vi) There is absence of any law regarding participation of fund holders in decisions concerning portfolio selection (vii) Grievance redressal has not been effective (viii) Management cost charged to the funds have been high, are than loaded on two derived factors factor 1,2 has an eigen value of 3.342 and 1.330 The total variance accounted by the four factors is 58.403, which is acceptable and thus establishes the validity of the study.

TABLE 11

FACTOR AND VARIANCE ANALYSIS

\begin{tabular}{|c|c|c|c|}
\hline \multirow{2}{*}{ Component } & Initial Eigen values & \multirow{2}{*}{$\%$ of Variance } & \multirow{2}{*}{ Cumulative \% } \\
\cline { 2 - 3 } & Total & 41.780 & 41.780 \\
\hline F1 & 3.342 & 16.623 & 58.403 \\
\hline
\end{tabular}

\section{Naming the Factors}

The two factors extracted have been named on the basis of various variables included in each case. The factors F1 and $\mathrm{F} 2$ have been named as

F1 - Regulation and control of mutual funds and

F2 - Under performance by mutual funds

The structure of these two factors has been discussed individually in detail here.

TABLE 12

REGULATION AND CONTROL OF MUTUAL FUNDS (F1)

\begin{tabular}{|l|l|c|}
\hline Labels & \multicolumn{1}{|c|}{ Variables } & Loading \\
\hline DE7 & Grievance redressal has not been effective & 0.839 \\
\hline DE5 & $\begin{array}{l}\text { Non understanding of certain technical terms and conditions permits the withdrawal of } \\
\text { scheme by the fund abruptly }\end{array}$ & 0.765 \\
\hline DE3 & Growth in the unit value has been very low & 0.718 \\
\hline DE8 & Management cost charged to the funds have been high & 0.690 \\
\hline
\end{tabular}

The rotated matrix has revealed their factor as most important with the highest Eigen value 3.342. In total, four variables have been loaded on their factor and are arranged according to their loading values. The variables composing this factor, with their labels and factor loadings are given in the above table.

The Table 12 reveals that the variable "Grievance redressal has not been effective" and it has got the highest loading of 0.839 . This is closely followed by the variables "Non understanding of certain technical terms and conditions permits the withdrawal of scheme by the fund abruptly" (0.765),"Growth in the unit value has been low" (0.718) and "Management cost charged to the funds" have a loading of 0.690 .
The pattern of variable loadings shows close association between the second and the third variables.

This factor describes the reasons for the withdrawal of mutual funds from the minds of general investors who feel that different regulatory bodies like SEBI and others have to heavily concentrate on regulating and controlling the working of different mutual funds so as to safeguard the small investors' interest. For the improvement of mutual fund the effective use of grievance redressal was said to be the major factor and also the factor describes the feeling of the investor about inefficient management of the mutual funds by fund managers. The grudge is about the higher management cost charged to the fund and provision of inefficiency after sale services.

TABLE 13

UNDER-PERFORMANCE BY MUTUAL FUNDS (F2)

\begin{tabular}{|c|l|c|}
\hline Labels & \multicolumn{1}{|c|}{ Variables } & Loading \\
\hline DE2 & Professionally qualified expert managers have under-performed & 0.889 \\
\hline DE1 & Returns from Mutual fund have been less than expected & 0.741 \\
\hline DE4 & $\begin{array}{l}\text { There is insecurity of investment due to connivance between fund managers } \\
\text { and corporate houses }\end{array}$ & 0.682 \\
\hline
\end{tabular}




\begin{tabular}{|c|l|c|}
\hline DE6 & $\begin{array}{l}\text { There is absence of any law regarding participation of fund holders in } \\
\text { decisions concerning portfolio selection }\end{array}$ & 0.545 \\
\hline
\end{tabular}

The rotated matrix has revealed their factor as the second most important with Eigen value of 1.330. In total, three variables have been loaded on their factor and are arranged according to their loading values. The variables composing this factor, with their labels and factor loadings are given.

The above Table 13 reveals that the variable "Professionally experts managers have under performed" and this category has got the highest loading of 0.889 . This is followed by the variable "Returns from MF which have been less than expected" (0.741) and "In security of investment due to collusion between fund managers and corporate houses" with a loading of 0.682 and the variable "There is absence of any law regarding participation of fund holders in decisions concerning portfolio selection" with the loading of 0.545 . This factor clearly brings out the fact of preference for high return on investment by mutual fund investor, which has been corroborated by weight age given to this variable earlier also. The investor feels that professionally qualified expert managers have not been able to perform efficiently as expected.

\section{CONCLUSION}

To conclude this discussion, it could be said that investors generally feel that regulatory bodies like SEBI and AMFI have to keep more concentration on controlling the working of mutual funds properly and the legal framework is not appropriately designed. Moreover, the funds have under-performed as against expectation and management has been inefficient, thereby discouraging investors to keep their funds parked in mutual funds.

\section{REFERENCES}

[1] Vaid, S. (1994). Mutual fund operations in India. Varanasi, India: Rishi Publication.

[2] Kothari C.R. (2003). Research methodology, methods and techniques. New Delhi, India: New Age International (P) Ltd.

[3] CRISIL Research. (2010). CRISIL-AMFI mutual fund performance insight. Available at:

https://www.amfiindia.com/Themes/Theme1/downloads/ CRISIL-AMFI_singles.pdf.

[4] CRISIL. (2014). CRISIL mutual fund year book. Available at: www.crisil.com

[5] Dhimen J. Jani \& Rajeev Jain. (2014). Measuring risk adjusted return (Sharpe ratio) of the selected mutual funds-A case of daily returns. Journal of Business Management \& Social Sciences Research (JBM\&SSR), 3(4), 43-45. 